\title{
PENDUGAAN PARAMETER GENETIK DAN KOMPONEN RAGAM KAMBING KACANG
}

\section{ESTIMATION OF GENETIC PARAMETERS AND COMPONENTS OF VARIANCE KACANG GOATS}

\author{
Simon Elieser ${ }^{1)}$ Muhammad Ary Syaputra ${ }^{2)} \operatorname{Hamdan}^{3)}$ dan Sayed Umar ${ }^{3)}$ \\ ${ }^{1}$ Kepala Loka Penelitian Kambing Potong Sei Putih Galang Deli Serdang, \\ ${ }^{2}$ Mahasiswa Program Studi Peternakan Fakultas Pertanian Universitas Sumatera Utara, \\ ${ }^{3}$ Staf Pengajar Program Studi Peternakan Fakultas Pertanian Universitas Sumatera Utara
}

\begin{abstract}
This research aimed to estimate value of genetic parameters and components variance of kacang goats. This research was conducted in goat center Sei Putih, Medan. In June - August 2015. The research material consists kacang goat production records for one generation as much as 20 goats $(9$ males and 11 female). The variables measured are birth weight, weight of 3, 6, 9 and 12 month. Heritability and genetic correlations were estimated using a nested design unbalanced and breeding value was calculated using the single measurement it self.The results showed that the coefficient variance of birth weight, 3,6, 9 and 12 month were 33\%; 26\%; 21\%; 26\% and 30\%, respectively. Heritability of birth weight, weight 3,6 month were 0,05; 0,03; and 0,04 , respectively. Genetic correlation value birth weight - weight at 3; 6; 9 and 12 month (0,55\%; 0,34\%; 0,28\%; 0,25\%), weight 3 - weight at 6; 9 and 12 month $(0,41 \%$; $0,54 \% ; 0,56 \%)$, weight 6 - weight at 9 and 12 month $(0,84 \% ; 0,64 \%)$, weight 9 - weight at 12 month $(0,83 \%)$. The conclusion of the study are coefficient variance of growth traits categorized high, but heritability is low and genetic correlation is moderate to high category.
\end{abstract}

Keywords : Kacang goats, genetic parameters, components of variance

\begin{abstract}
ABSTRAK
Penelitian ini bertujuan untuk mengestimasi nilai parameter genetik dan komponen ragam pada kambing Kacang. Penelitian ini dilaksanakan diBalai Penelitian Kambing Potong Sei Putih, Galang pada bulan Juni 2015 sampai Agustus 2015. Materi penelitian terdiri dari catatan produksi kambing Kacang selama satu generasi sebanyak 20 ekor (9 ekor pejantan dan 11 ekor betina).Variabel yang diamati adalah bobot lahir, bobot 3, 6, 9 dan 12 bulan. Heritabilitas dan korelasi genetik diestimasi menggunakan pola tersarang (Nested disegn) model unbalanced dan nilai pemuliaan dihitung menggunakan pengukuran tunggal dirinya sendiri. Hasil penelitian menunjukkan bahwa nilai koefisien keragaman dari sifat bobot lahir, 3, 6, 9 dan 12 bulan berturut - turut-adalah 33\%; 26\%; $21 \% ; 26 \%$ dan $30 \%$. Nilai heritabilitas sifat bobot lahir,3 dan 6 bulan berturut - turut adalah 0,$05 ; 0,03$ dan 0,04 . Nilai korelasi genetik bobot lahir - bobot 3,6 dan 12 bulan $(0,55 \% ; 0,34 \% ; 0,28 \% ; 0,25 \%)$, bobot 3 bulan $-6,9$ dan 12 bulan $(0,41 \% ; 0,54 \%$; $0,56 \%)$, bobot $6-9$ dan 12 bulan $(0,84 \% ; 0,64 \%)$ dan bobot $9-12$ bulan $(0,83 \%)$. Kesimpulan dari penelitian ini menunjukkan nilai koefisien keragaman yang tinggi, nilai heritabilitas termasuk kategori rendah dan nilai korelasi genetik termasuk kategori sedang - tinggi.
\end{abstract}

Kata kunci : Kambing Kacang, parameter genetik, komponen ragam 


\section{PENDAHULUAN}

Kambing (Capra hircus) merupakan salah satu jenis ternak yang pertama dibudidayakan oleh manusia untuk keperluan sumber daging, susu, kulit dan bulu (Chen at al., 2005). Bukti arkeologi menemukan bahwa kambing merupakan hewan yang pertama didomestikasi di kawasan Asia Barat sekitar 10.000 tahun lalu (Zeder and Hesse, 2000).

Pengembangan subsektor peternakan khususnya produksi kambing dan domba masih tertinggal jauh dibandingkan dengan ternak besar seperti sapi dan kerbau, padahal masalah pengembangan produksi sangat dipengaruhi oleh ketersediaan bibit. Jenis bangsa kambing ini secara total populasi setiap tahunnya menurun. Dikwatirkan suatu saat kambing kacang ini akan punah apabila tidak dilaksanakan penggalian dan pelestarian kembali. Upaya pelestarian terhadap kambing sangat berhubungan terhadap penggunaan tekhnologi strategi peningkatan mutu genetik (Doloksaribu et al., 2005).

Kambing Kacang merupakan kambing asli Indonesia dengan populasi yang cukup banyak dan tersebar luas di wilayah pedesaan, kambing Kacang memiliki karakteristik sebagai berikut: ukuran tubuhnya relatif kecil, kepala ringan dan kecil, telinga pendek dan tegak lurus mengarah ke atas depan, memiliki daya adaptasi yang tinggi terhadap kondisi alam setempat dan performan reproduksinya sangat baik. Kambing Kacang banyak dijumpai juga di Filipina, Myanmar, Thailand, Malaysia (Murtidjo, 1993).

Salah satu upaya untuk meningkatkan produktivitas yaitu dengan melakukan perbaikan mutu genetik kambing melalui seleksi. Seleksi calon induk kambing Kacang dapat dilakukan melalui Nilai Pemuliaan (Hamid, 2002).

Berdasarkan uraian tersebut di atas maka perlu dilakukan penelitian untuk mengindentifikasi keragaman genetik yang mengontrol sifat pertumbuhan dan produksi pada kambing Kacang sebagai dasar informasi genetik yang dapat dimanfaatkan untuk mengembangkan strategi seleksi dan meningkatkan mutu genetik kambing Kacang yang ada di Loka Penelitian Kambing Potong, Sei Putih. 


\section{BAHAN DAN METODE PENELITIAN}

\section{Tempat dan Waktu Penelitian}

Penelitian ini dilaksanakan di kandang percobaan Loka Penelitian Kambing Potong Kecamatan Galang Kabupaten Deli Serdang Provinsi Sumatera Utara. Penelitian dilakukan mulai bulan Juni-Agustus 2015.

\section{Bahan dan Alat Penelitian}

\section{Bahan}

Materi penelitian adalah anak kambing Kacang generasi pertama sebanyak 20 ekor dengan 9 ekor pejantan dan 11 ekor betina.

Penelitian ini dilakukan dengan menggunakan data primer dan data sekunder. Data primer diperoleh dari pengamatan langsung (penimbangan berat badan tertentu) sedangkan data sekunder (nomor dan bangsa tetua, bobot induk kawin dan melahirkan, tanggal kawin, tanggal lahir, nomor anak, jenis kelamin dan tipe kelahiran) diperoleh dari catatan atau recording kambing Kacang di Loka Penelitian Kambing Potong.

\section{Alat}

Pada penelitian ini digunakan timbangan merk shelter kapasitas $50 \mathrm{~kg}$ dengan ketelitian $100 \mathrm{~g}$, buku catatan, kandang kelompok untuk induk menyusui, kandang kelompok umur lepas sapih serta perlengakapan ear tag.

\section{Metode Penelitian}

Metode yang digunakan adalah metode pengambilan data recording berupa data time series dalam 1 generasi. Data recording ini diperoleh dari instansi terkait dengan menggunakan data time series yaitu nomor dan bangsa tetua, tanggal kawin, tanggal lahir, nomor anak, jenis kelamin, bobot lahir sampai bobot 12 bulan pada bangsa kambing Kacang dalam 1 generasi.

\section{Parameter penelitian}

\section{Sifat Kuantitatif}

\section{a. Bobot lahir}

Bobot lahir adalah bobot cempe yang baru lahir ditimbang tidak melebihi 24 jam. Bobot lahir merupakan faktor yang memengaruhi pertumbuhan dan produksi ternak saat dewasa (Hamid, 2002). 


\section{b. Bobot 3 bulan}

Bobot sapih adalah bobot pada saat anak tidak diberi susu (umur 90 hari). Bobot sapih sangat dipengaruhi oleh faktor induk (maternal) tetapi pengaruh tersebut menunjukkan penurunan dengan semakin meningkatnya umur ternak. Selain faktor genetik, bobot sapih juga dipengaruhi oleh faktor induk atau maternal tetapi pengaruh tersebut menunjukkan penurunan dengan meningkatnya umur ternak.

\section{c. Bobot 6 bulan}

Pertambahan bobot badan lepas sapih juga dipengaruhi oleh lingkungan dan kemampuan individu ternak. Lingkungan yang nyaman dan optimal sesuai kebutuhan ternak berpengaruh pada produktifitas ternak. Pertambahan bobot badan lepas sapih dihitung mulai umur 6 bulan.

\section{d. Bobot 9 bulan}

Bobot 9 bulan yaitu penimbangan bobot badan ternak pada umur 9 bulan.

\section{e. Bobot 12 bulan}

Bobot 12 bulan yaitu penimbangan bobot badan ternak pada umur 12 bulan.

\section{Komponen Ragam}

Rumus bobot badan terkoreksi menurut Kurnianto (2010) adalah:

$$
\begin{aligned}
\mathrm{BL}_{\mathrm{T}} & =\mathrm{BL} \times \mathrm{FKJK} \times \mathrm{FKTK} \\
\mathrm{BS}_{\mathrm{T}} & =\mathrm{BS} \times \mathrm{FKJK} \times \text { FKTK } \\
\mathrm{BLS}_{\mathrm{T}} & =\mathrm{BLS} \times \text { FKJKx FKTK }
\end{aligned}
$$

Keterangan:

$$
\begin{aligned}
& \mathrm{BL}_{\mathrm{T}}=\text { Bobot Lahir Terkoreksi } \\
& \mathrm{BL}=\text { Bobot Lahir } \\
& \mathrm{BLS}=\text { Bobot LepasSapih } \\
& \mathrm{BLS}_{\mathrm{T}}=\text { Bobot Lepas Sapih Terkoreksi } \\
& \mathrm{BS}_{\mathrm{T}}=\text { Bobot Sapih Terkoreksi } \\
& \mathrm{BS}=\text { Bobot Sapih } \\
& \text { FKTK }=\text { Faktor Koreksi Tipe Kelahiran } \\
& \text { FKJK }=\text { Faktor Koreksi Jenis kelamin }
\end{aligned}
$$




\section{a. $\operatorname{Ragam}\left(\sigma^{2}\right)$}

Jumlah kuadrat dari selisih nilai data observasi dengan mean dibagi banyaknya data observasi. Rumus perhitungan nilai ragam untuk populasi menurut (Supramono dan Sugiarto, 1993).

$$
\sigma^{2}=\frac{\sum\left(x_{i}-\mu\right)^{2}}{N}
$$

Keterangan :

$\sigma^{2}=$ Ragam untuk populasi

$\mathrm{N}$ = Banyaknya data populasi

$\mathrm{Z} \mu=$ Rata-rata populasi

\section{b. Koefisien Keragaman (KK)}

Koefisien keragaman dihitung dengan rumus menurut Kurnianto (2010) sebagai berikut :

$\mathrm{KK}=\frac{\sigma}{\mu}(100 \%)$

Keterangan :

$\mu=$ Rata-rata populasi

$\sigma=$ Standart deviasi untuk populasi

$\mathrm{KK}=$ Koefisien keragaman

\section{c. Peragam}

Untuk mengetahui bentuk hubungan dan keeratan hubungan antara 2 parameter atau variabel. Rumus peragam (Kurnianto, 2010).

$\mathrm{S}_{\mathrm{xy}}=\frac{\sum X Y}{n-1}=\frac{\sum X Y-\left\{\left[\left(\sum X\right)\left(\sum Y\right)\right] / n\right\}}{n-1}$

\section{Nilai Heritabilitas $\left(\mathbf{h}^{2}\right)$}

Nilai Heritabilitas menggunakan data Bobot Laihr, Bobot Sapih dan Bobot Lepas Sapih pada ternak kambing kacang.

Maka, nilai heritabilitas dapat dihitung dengan persamaan:

$$
\begin{aligned}
h^{2} S & =\frac{4 \sigma^{2} s}{\left(\sigma^{2} s+\sigma^{2} d+\sigma^{2} w\right)} \\
h^{2} D & =\frac{4 \sigma^{2} d}{\left(\sigma^{2} s+\sigma^{2} d+\sigma^{2} w\right)}
\end{aligned}
$$

(Kurnianto, 2010). 


\section{Estimasi Korelasi Genetik (rG)}

Estimasi Korelasi Genetik dengan menggunakan data bobot Lahir, bobot umur 3 bulan, 6 bulan, 9 bulan dan 12 bulan pada ternak kambing kacang.

Korelasi genetik $\left(\mathrm{r}^{\mathrm{g}}\right)=\frac{4 \operatorname{Cov} \mathrm{s}}{\sqrt{4 \sigma^{2} \mathrm{~s}(\mathrm{X}) \cdot 4 \sigma^{2} \mathrm{~s}(\mathrm{Y})}}$

(Kurnianto,2010)

\section{Estimasi Nilai Pemuliaan (Estimated Breeding Value)}

Menurut Kurnianto (2010), nilai pemuliaan dapat ditaksir dengan menggunakan satu catatan produksi dari 1 individu, yaitu :

$$
\mathbf{E B V}=\mathbf{h}^{2}\left(\mathbf{P}_{\mathbf{i}}-\overline{\mathbf{P}_{\mathbf{p}}}\right)
$$

Keterangan :

$\mathrm{EBV}=$ Estimated Breeding Value

$\mathrm{h}^{2} \quad=$ Nilai heritabilitas sebagai pembobot

$\mathrm{P}_{\mathrm{i}} \quad=$ Produksi dari catatan tunggal ternak yang sedang dihitung NP nya

$\overline{\mathrm{P}}_{\mathrm{p}}=$ rata- rata produksi dari ternak - ternak pembanding (ternak - ternak lain yang berproduksi pada tempat dan waktu yang sama).

\section{Analisis Data}

Analisis terhadap sifat kuantitatif (bobot badan nyata dan terkoreksi) heritabilitas dan nilai pemuliaan dilakukan dengan program Microsoft Excel, sedangkan nilai korelasi genetik dilakukan dengan bantuan program SPSS versi $17 \mathrm{~s}$.

\section{HASIL DAN PEMBAHASAN}

Sesuai analisis statistik hasil penelitian dapat dilihat pada table rekapitulasi. Hasil penelitian sebagai berikut :

\section{Bobot Lahir}

Hasil analisis terhadap kambing Kacang bobot lahir, yaitu pada anak jantan $(1,82 \pm 0,58 \mathrm{~kg})$ dan betina $(1,61 \pm 0,56 \mathrm{~kg})$ lebih rendah dibandingkan penelitian Mahmilia dan Andi (2014) yaitu sebesar $(2,21 \pm 0,51 \mathrm{~kg})$ pada jantan dan $(2,01 \pm 0,52 \mathrm{~kg})$ untuk betina.

Berdasarkan jenis kelamin bobot lahir kambing jantan lebih besar dibandingkan kambing betina. hal ini berkaitan oleh pernyataan Toelihere (1981). 
Tabel 1. Rekapitulasi Data Parameter Genetik dan Komponen Ragam Kambing Kacang

\begin{tabular}{lcccc}
\hline \multicolumn{1}{c}{ Sifat Pertumbuhan } & \multicolumn{2}{c}{ Komponen ragam } & \multicolumn{2}{c}{ Parameter Genetik } \\
\cline { 2 - 5 } & ragam & $\begin{array}{c}\text { Koefisien } \\
\text { Keragaman }\end{array}$ & $\begin{array}{c}\text { Nilai } \\
\text { Heritabilitas }\end{array}$ & $\begin{array}{c}\text { Korelasi } \\
\text { genetic }\end{array}$ \\
\hline Bobot lahir & 0,32 & 33 & 0,05 & - \\
Bobot lahir terkoreksi & 0,45 & 32 & - & - \\
Bobot 3 bulan & 2,87 & 26 & 0,03 & - \\
Bobot 3 bulan terkoreksi & 4,25 & 19 & - & - \\
Bobot 6 bulan & 1,82 & 21 & 0,04 & - \\
Bobot 6 bulan terkoreksi & 4,20 & 19 & - & - \\
Bobot 9 bulan & 8,03 & 26 & - & - \\
Bobot 9 bulan terkoreksi & 10,14 & 25 & - & - \\
Bobot 12 bulan & 24,31 & 30 & - & - \\
Bobot 12 bulan terkoreksi & 30,95 & 29 & - & - \\
Bobot lahir-Bobot 3 bulan & - & - & - & 0,55 \\
Bobot lahir-Bobot 6 bulan & - & - & - & 0,34 \\
Bobot lahir-Bobot 9 bulan & - & - & - & 0,28 \\
Bobot lahir-Bobot 12 bulan & - & - & - & 0,25 \\
Bobot 3 bulan-Bobot 6 bulan & - & - & - & 0,41 \\
Bobot 3 bulan-Bobot 9 bulan & - & - & - & 0,54 \\
Bobot 3 bulan-Bobot 12 bulan & - & - & - & 0,56 \\
Bobot 6 bulan-Bobot 9 bulan & - & - & - & 0,84 \\
Bobot 6 bulan-Bobot 12 bulan & - & - & - & 0,64 \\
Bobot 9 bulan-Bobot 12 bulan & - & - & - & 0,83 \\
\hline
\end{tabular}

yang menyatakan bahwa plasenta jantan lebih besar dibandingkan plasenta betina dengan demikian kesempatan fetus jantan untuk memperoleh zat makanan cukup banyak jika dibandingkan dengan yang betina.

Menurut Hardjosubruto (1994), bobot lahir jantan lebih besar daripada bobot lahir betina hal ini karena pengaruh hormon testosteron yang mendorong tingginya nafsu makan pada jantan.

Anak kambing dengan tipe kelahiran tunggal memiliki bobot lahir yang tinggi dibandingkan anak tipe kelahiran kembar dengan nilai masing - masing adalah $(1,88 \pm 0,6 \mathrm{~kg})$ dan $(1,45 \pm 0,4 \mathrm{~kg})$.

Tujuan data dikoreksi yaitu untuk mengurangi keragaman data yang disebabkan oleh faktor lingkungan berupa jenis kelamin, tipe kelahiran dan umur induk. 


\section{Bobot 3 bulan}

Rataan bobot badan 3 bulan kambing kacang berdasarkan jenis kelamin yaitu $(7,26 \pm 1,84 \mathrm{~kg})$ pada jantan dan $(5,7 \pm 1,28 \mathrm{~kg})$ pada betina. Hal ini berkaitan dengan sifat fetus jantan yang yang lebih baik dalam menyerap nutrisi induk dibandingkan betina (Davendra and Burns,1994). Bobot sapih banyak dipengaruhi oleh bobot lahir yaitu banyaknya susu induk, jenis kelamin dan banyaknya anak dalam satu kelahiran (Lasley,1978). Pada penelitian ini anak dengan tipe kelahiran kembar lebih tinggi dibandingkan tipe kelahiran tunggal masing - masing yaitu kembar jantan $(6,13 \pm 0,68 \mathrm{~kg})$ dan betina $(6,20 \pm 1,43 \mathrm{~kg})$.

\section{Bobot 6 bulan}

Hasil analisis terhadap bobot 6 bulan kambing kacang yaitu berkisar $(9,6 \pm 1,58 \mathrm{~kg})$ pada jantan dan $(7,83 \pm 1,66 \mathrm{~kg})$ pada betina. Pada penelitian ini anak dengan tipe kelahiran tunggal lebih tinggi dibandingkan tipe kelahiran kembar masing - masing yaitu $(8,88 \pm 1,93 \mathrm{~kg})$ dan $(8,35 \pm 1,76 \mathrm{~kg})$. Hal ini sesuai dengan pernyataan Gatenby (1986) yang menyatakan bahwa liter size tunggal pertumbuhannya lebih cepat dibandingkan liter size kembar hal ini bisa terjadi karena zat makanan yang diberikan induk tidak terbagi secara merata.

\section{Bobot 9 bulan}

Hasil analisis terhadap bobot 9 bulan kambing kacang yaitu berkisar $(12,6 \pm 2,57 \mathrm{~kg})$ pada jantan dan $(9,0 \pm 2,0 \mathrm{~kg})$ pada betina. Pada penelitian ini anak dengan tipe kelahiran kembar lebih tinggi dibandingkan tipe kelahiran tunggal masing - masing yaitu $(10,15 \pm 2,61 \mathrm{~kg})$ dan $(9,99 \pm 2,61 \mathrm{~kg})$.

\section{Bobot 12 bulan}

Hasil analisis terhadap bobot 12 bulan kambing kacang yaitu berkisar $(20,2 \pm 3,13 \mathrm{~kg})$ pada jantan dan $(12,5 \pm 2,91 \mathrm{~kg})$ pada betina. Pada penelitian ini anak dengan tipe kelahiran tunggal lebih tinggi dibandingkan tipe kelahiran kembar masing - masing yaitu $\quad(16,31 \pm 4,71 \mathrm{~kg})$ dan $(15,52 \pm 5,53 \mathrm{~kg})$.

\section{Estimasi Nilai Heritabilitas}

Hasil analisis statistik, nilai pewarisan sifat tetua terhadap keturunanya untuk bobot lahir, bobot 3 bulan dan bobot 6 bulan berturut - turut adalah 0,05, 0,03 dan 0,04. Pada penelitian ini memiliki nilai heritabilitas rendah, rendahnya nilai heritabilitas bukan hanya disebabkan olah rendahnya variasi genetik namun 
lebih banyak ditentukan oleh tingginya variasi lingkungan ( Pakan dan manajemen pemeliharaan). Heritabilitas merupakan perbandingan antara ragam genetik terhadap ragam fenotipik. Sifat produksi yang memiliki nilai heritabilitas rendah adalah sifat dimana semua keragaman fenotipik pada ternak disebabkan semata-mata oleh pengaruh faktor lingkungan, dan diasumsikan pengaruh genetik sedikit.

Angka pewarisan ketiga sifat tersebut tergolong rendah sehingga tidak layak untuk dijadikan acuan program seleksi. Nilai heritabilitas dikatakan rendah $(0-0,1)$. Suatu sifat jika memiliki nilai heritabilitas yang tinggi, apabila digunakan untuk seleksi maka akan menunjukkan respon seleksi yang tinggi. Tetapi pada angka pewarisan rendah, belum tentu keturunan akan mempunyai keunggulan dalam sifat tersebut karena keunggulan dari ternak tersebut sebagian besar disebabkan oleh faktor lingkungan (Hardjosubroto, 1994).

\section{Korelasi Genetik}

Berdasarkan hasil penelitian didapatkan nilai korelasi genetik keseluruhan bernilai positif. Hal ini sesuai dengan pendapat Noor (1996) yang menyatakan bahwa korelasi genetik yang positif ada jika seleksi untuk satu sifat tidak saja berakibat diperbaikinya sifat tersebut dan nilai korelasi berkisar antara -1 dan +1 yang disebut sebagai korelasi sempurna, sebab setiap penurunan atau peningkatan variable $\mathrm{x}$ akan diikuti oleh peningkatan atau penurunan variabel y dalam jumlah unit yang sama.

Nilai korelasi antara bobot 6 bulan-bobot 9 bulan yaitu sebesar 0,84\%; lebih tinggi dibandingkan korelasi bobot lahir - bobot kambing 3 bulan $(0,55 \%)$, bobot 6 bulan $(0,34 \%)$, bobot 9 bulan $(0,28 \%)$, dan bobot 12 bulan $(0,25 \%)$, korelasi pada bobot 3 bulan - bobot 6 bulan $(0,41 \%)$, bobot 9 bulan $(0,54 \%)$, dan bobot 12 bulan $(0,56 \%)$, dan korelasi pada bobot 6 bulan - bobot 12 bulan $(0,64 \%)$, serta korelasi pada bobot 9 bulan - bobot 12 bulan (83\%).

Korelasi genetik menunjukkan arah positip dan berderajat tinggi sehingga menunjukkan hubungan yang erat antar peubah. Hal tersebut disebabkan karena antar sifat-sifat pada umur yang sama dikontrol oleh gen-gen yang sama pada waktu yang bersamaan sehingga memperkecil peragam lingkungan dan sebaliknya meningkatkan peragam genetik aditif. Estimasi korelasi genetik aditif 
dan penotipik pada performans pertumbuhan bernilai positif dan tinggi sehingga menunjukkan tidak adanya antagonisme antara sifat-sifat pertumbuhan pada saat lahir (Zhang et al., 2009).

\section{Nilai Pemuliaan (estimated breeding value)}

Nilai pemuliaan bobot lahir, bobot 3 bulan dan bobot 6 bulan dari 9 ekor anak jantan dan 11 ekor anak betina kambing kacang. Nilai pemuliaan positif berada diatas rata-rata kelompok, sedangkan nilai pemuliaan negatif berada dibawah rata - rata kelompok.

Anak kambing Kacang jantan yang memiliki nilai pemuliaan bobot lahir diatas rata sebanyak 66\% atau 6 ekor dengan kode yaitu: 41001, 41007, 41008, 41013, 41030, dan 41031. Pada bobot 3 bulan sebanyak 6 ekor dengan kode yaitu : 41001, 41002, 41011, 41013,41030, dan 41031. Sedangkan pada bobot 6 bulan hanya sebanyak 55\% atau 5 ekor dari populasi dengan kode yaitu: 41001, 41002, 41007, 41008, dan 41030.

Anak betina yang memiliki nilai pemuliaan bobot lahir dan bobot 3 bulan diatas populasi rata-rata sebanyak $45 \%$ atau 5 ekor dengan kode yaitu : (41003, 41006, 41017, 41024, dan 41029) dan (41003, 41017, 41018, 41024, dan 41034). Sedangkan pada bobot 6 bulan hanya sebanyak 36\% atau 4 ekor dari rata-rata populasi dengan kode yaitu : 41003, 41009, 41024, dan 41034.

Nilai pemuliaan yang lebih tinggi menunjukkan kemampuan kambing sampel untuk mewariskan potensi genetik kepada keturunannya dan mengulang produksinya lebih baik Nugraha (2007). Kondisi ini didukung dengan pernyataan Dakhlan dan Sulastri (2002) yakni individu dengan NP yang tinggi akan menunjukkan kemampuannya untuk mewariskan potensi genetik kepada keturunannya dan mengulang produksi-nya.

Sebanyak 5 ekor jantan dan 5 ekor betina kambing kacang memiliki nilai indeks diatas rata - rata populasi, berturut - turut pada jantan dan betina adalah : (41030, 41002, 41001, 41008, 41031) dan (41024, 41003, 41034. 41029, 41017). Dengan demikian, nomor individu dengan rangking tertinggi mempunyai potensi genetik sebagai ternak seleksi untuk perbaikan mutu genetik dalam populasi ternak kambing kacang. 


\section{KESIMPULAN}

Nilai heritabilitas bobot lahir, bobot 3 bulan dan bobot 6 bulan pada anak kambing kacang masih tergolong rendah, sedangkan untuk nilai korelasi genetik antara sifat bobot lahir sampai bobot 12 bulan tergolong tinggi dan nilai pemuliaan kambing Kacang (jantan dan betina) di atas rata - rata popilasi dapat digunakan sebagai dasar seleksi untuk perbaikan mutu genetik pada generasi berikutnya.

\section{DAFTAR PUSTAKA}

Dakhlan, A. dan Sulastri. 2002. Ilmu Pemuliaan Ternak. Buku Ajar. Jurusan Produksi Ternak, Fakultas Pertanian, Universitas Lampung. Bandar Lampung.

Chen, S. Y., Y. H. Su, S. F. Wu, T. Sha and Y. P. Zhang. 2005. Mitochondrial diversity and phylogeographic structure of Chinese domestic goats. Molecular phylogenetics and Evolution. 37: 804-814.

Davendra, C. dan Burn. 1994. Produksi Kambing di Daerah Tropik,Diterjemahkan oleh IDK Harya Putra. Institut Teknologi Bandung. P. 32, 117- 122

Doloksaribu, M.,et al.2005. Produktivitas Kambing Kacang pada Kondisi dikandangkan :1. Bobot lahir, bobot sapih, jumlah anak sekelahiran dan daya hidup anak prasapih. Seminar Nasional Teknologi Peternakan dan Veteriner. 581.Loka Penelitian Kambing Potong, Galang Sungei Putih, Deli Serdang.

Gatenby, R. M. 1986. Sheep Production in the Tropics and Subtropics. $1^{\text {sd }}$ Ed. Longman Singapore Publishers (Pte). Ltd. Singapore.

Hamid, F, at al. 2002. Seleksi calon induk berdasarkan nilai pemuliaan bobot sapih kambing kacang di Kecamatan Natar, Kabupaten Lampung Selatan. Universitas Lampung. Lampung.

Harjosubroto, W. 1994. Aplikasi Pemuliaan Ternak di lapangan. Grasindo. Jakarta.

Kurnianto, E. 2010. Ilmu Pemuliaan Ternak. Lembaga Pengembangan dan Penjaminan Mutu Pendidikan.Universitas Diponegoro.Semarang. 
Lasley, 1978. Genetics of Livestock Improvement, third edition Printice-Hall of India Private Limited, New Delhi.

Mahmilia F. Dan A. Tarigan. 2005. Karakteristik Morfologi dan Performans Kambing Kacang, Kambing Boer dan Persilangannya. Lokakarya Nasional Kambing Potong. http://peternakan.litbang.deptan.go.id. Halaman 212.

Nugraha, H. A. 2007. Perbandingan Potensi Genetik dan Kemampuan mewariskan Sifat - sifat Pertumbuhan Berdasarkan Nilai Pemuliaan (Breeding Value) pada Pejantan Boer dan Boerawa. Skripsi. Fakultas Pertanian. Universitas Lampung.

Noor, R.R. 1996. Genetika Ternak. Ed ke-1. Jakarta : Penebar Swadaya.

Supramono dan Sugiarto.1991. Statistika. Edisi 1. Andi offset. Yogyakarta.

Toelihere M.1981. fisiologi Reproduksi pada Ternak. Angkasa Bandung.

Zhang CY, Zhanga Y, Xu DQ, Li X, Su J, Yang LG. 2009. Genetic and phenotypic parameter estimates for growth traits in Boer goat. Lives Sci 124: $66-71$

Zeder, M.A. and B. Hesse. 2000. The initial domestication of goats (Capra hircus) in the Zagros Mountain 10,000 years ago. Science 287: 2254-2257. 